\title{
Pengaruh Kualitas Pelayanan dan Kepuasan Pelanggan Terhadap Loyalitas Pelanggan pada Hotel Libra Kadipaten Kabupaten Majalengka
}

\author{
Tia Aprilia Susnita \\ STIE STMY Majalengka \\ tiasusnita@gmail.com
}

\begin{abstract}
Abstrak
Maksud dari mengadakan penelitian ini adalah untuk mengumpulkan informasi yang akan digunakan untuk menganalisis pengaruh kualitas pelayanan dan kepuasan pelanggan terhadap loyalitas pelanggan pada Hotel Libra Kadipaten Kabuaten Majalengka. Dan diharapkan dapat mebantu perusahaan dalam menyelesaikan masalah yang dihadapi sesuai dengan topik yang diambil penulis, dengan cara menganalisis, khususnya informasi dan data mengenai pengaruh kualitas pelayanan dan kepuasan pelanggan terhadap loyalitas pelanggan. Dalam penelitian ini metode yang digunakan adalah deskriptif dan pendekatan kuantitatif. Populasi dalam penelitian ini adalah seluruh pelanggan Hotel Libra Kadipaten Kabuaten Majalengka. Menurut data dari HRD Hotel Libra Kadipaten Kabupaten Majalengka, jumlah pelanggan pada tahun 2018 sebanyak 10690 orang. Sampel dalam penelitian ini adalah 99 responden. Analisis data yang digunakan adalah analisis regresi berganda, korelasi berganda, koefisien determinasi uji $\mathrm{f}$ dan uji t. Terdapat pengaruh positif dan signifikan kualitas pelayanan terhadap loyalitas pelanggan. Terdapat pengaruh positif dan signifikan kepuasan terhadap loyalitas pelanggan.Kualitas pelayanan dan kepuasan secara bersama-sama berpengaruh positif dan signifikan terhadap loyalitas pelanggan. Karena nilai $F_{\text {hitung }}(63,965)>F_{\text {tabel }}(3,09)$, sehingga $\mathrm{H} 0$ ditolak dan Ha diterima, artinya kualitas pelayanan dan kepuasan secara bersama-sama berpengaruh positif dan signifikan terhadap loyalitas pelanggan pada Hotel Libra Kabupaten Majalengka.
\end{abstract}

Kata kunci : kualitas pelayanan, kepuasan dan loyalitas pelanggan 


\section{PENDAHULUAN}

Industri perhotelan adalah industri jasa yang memadukan antara produk dan layanan. Desain bangunan, interior dan eksterior kamar hotel serta restoran, suasana yang tercipta di dalam kamar hotel, restoran serta makanan dan minuman yang dijual beserta keseluruhan fasilitas yang ada merupakan contoh produk yang dijual. Sedangkan layanan yang dijual adalah keramah-tamahan dan keterampilan staff/karyawan hotel dalam melayani pelanggannya. Kotler dan Amstrong (2014:219) mendefinisikan jasa sebagai aktivitas atau manfaat yang ditawarkan oleh satu pihak lain yang pada dasarnya tanpa wujud dan tidak menghasilkan kepemilikan apapun. Definisi jasa adalah suatu kegiatan yang memilki beberapa unsur ketidakberwujudan (intangibility) yang melibatkan beberapa interaksi dengan konsumen atau properti dalam kepemilikannya, dan tidak menghasilkan transfer kepemilikan.

Keberhasilan suatu perusahaan ditentukan oleh bagaimana suatu perusahaan mampu memuaskan pelanggannya. Pada dasarnya pelanggan hanya menginginkan kepuasan dari apa yang mereka dapatkan. Pelanggan akan merasa puas jika barang atau jasa yang mereka dapatkan mampu memenuhi harapannya. Apabila sebuah perusahaan mampu memberikan kepuasan bagi pelanggannya, maka perusahaan tersebut tidak hanya mempunyai pelanggan yang setia, akan tetapi pelanggan yang merasa puas akan memberikan rekomendasi kepada pelanggan lain.

Bersamaan dengan adanya perubahan lingkungan yang terjadi dan adanya perubahan perilaku manusia, maka semakin mendorong bertambahnya akan kebutuhan pemakaian jasa hotel. Semakin bertambahnya permintaan akan pemakaian jasa hotel ini mendorong para pengusaha dibidang jasa perhotelan dalam hal ini Hotel Libra Kadipaten Kabuaten Majalengka itu sendiri yang dapat diberikan oleh perusahaan sehingga pelanggan merasa puas.

Loyalitas konsumen merupakan tujuan utama para perusahaan untuk mengembangkan bisnisnya, kekuatan konsumen sebagai salah satu kunci sukses dalam bisnis. konsumen yang loyal pada perusahaan akan memberikan prioritas utama dalam bertransaksi. Loyalitas konsumen berkaitan erat terhadap kualitas layanan dan kepuasan atau ketidakpuasan yang dialami oleh konsumen.

Kualitas layanan dalam sebuah perusahaan dapat menentukan berlangsung nya ikatan perusahaan dengan konsumen dalam jangka panjang. Menurut Tjiptono, (2014:59) kualitas layanan adalah tingkat keunggulan yang diharapkan dan pengendalian atas tingkat keunggulan tersebut untuk memenuhi kebutuhan konsumen. Menurut Nasution (2015:54) Jika layanan yang diterima atau dirasakan sesuai dengan yang diharapkan, maka kualitas layanan dipersepsikan baik dan memuaskan.

Jadi dapat disimpulkan Kualitas layanan merupakan suatu usaha yang dilakukan perusahaan dengan memberikan pelayanan sebaik mungkin untuk memenuhi kebutuhan konsumennya sehingga akan menimbulkan kepuasan kepada konsumen yang menerimanya. 
Kepuasan konsumen merupakan perasaan senang atau kecewa dari konsumen yang berasal dari perbandingan antara kinerja perusahaan dengan harapannya. Konsumen yang puas akan melakukan pembelian ulang diperusahaan tersebut dan mereka akan merekomendasikan pada orang lain atas apa yang mereka rasakan. Kepuasan konsumen merupakan faktor yang sangat menentukan dalam citra perusahaan, kekecewaan konsumen dalam menerima layanan bias menjadikan kehancuran perusahaan dimasa mendatang. Agar konsumen dapat dipertahankan, tentu harus dilakukan layanan optimal bagi konsumen dan untuk menciptakan kepuasan konsumen perusahaan dituntut untuk melakukan berbagai perubahan dalam hal ketersediaan sumber daya manusia, mutu layanan, maupun gedung yang bersih dan nyaman. Berbagai perubahan tersebut diharapkan dapat menciptakan kepuasan konsumen.

Kualitas pelayanan maupun kepuasan konsumen yang diterapkan oleh pihak hotel menjadi salah satu acuan dan faktor yang menentukan loyalitas konsumen Hotel Libra Kadipaten Kabuaten Majalengka sehingga penetapan standar kualitas pelayanan yang dilakukan pihak hotel begitu juga dengan kepuasan konsumen harus sesuai dengan harapan pengunjung. Hal tersebut dapat ditunjang oleh seluruh pihak Hotel Libra Kadipaten Kabuaten Majalengka.

Oleh karena itu perusahaan harus lebih memperhatikan terhadap situasi dan kondisi yang selalu berubah-ubah dan terus berusaha agar tetap dapat menunjukan keberhasilannya dipasaran. Jika kualitas pelayanan yang diberikan menurun maka sangat berpengaruh juga terhadap menurunnya tingkat kepuasan pengunjung yang pada akhirnya para pengunjung akan berpindah ke hotel lain..

\section{Rumusan Masalah}

Berdasarkan latar belakang yang telah diuraikan, maka penulis merumuskan beberapa masalah yang terdapat pada Hotel Libra Kadipaten Kabuaten Majalengka, sebagai berikut :

1. Bagaimana kualitas pelayanan pada Hotel Libra Kadipaten Kabuaten Majalengka?

2. Bagaimana kepuasan pelanggan pada Hotel Libra Kadipaten Kabuaten Majalengka?

3. Bagaimana loyalitas pelanggan pada Hotel Libra Kadipaten Kabuaten Majalengka?

4. Adakah pengaruh kualitas pelayanan terhadap loyalitas pelanggan pada Hotel Libra Kadipaten Kabuaten Majalengka?

5. Adakah pengaruh kepuasan pelanggan terhadap loyalitas pelanggan pada Hotel Libra Kadipaten Kabuaten Majalengka?

6. Adakah pengaruh kualitas pelayanan dan kepuasan pelanggan terhadap loyalitas pelanggan pada Hotel Libra Kadipaten Kabuaten Majalengka? 


\section{LANDASAN TEORI}

\section{Kerangka Pemikiran}

Kualitas pelayanan yang dihasilkan dari kinerja yang baik memiliki hubungan yang erat dengan kepuasan pelanggan. Kualitas memberikan suatu dorongan kepada pelanggan untuk menjalin ikatan hubungan yang kuat dengan perusahaan. Dalam jangka panjang, ikatan seperti ini memungkinkan perusahaan untuk memahami dengan seksama harapan serta kebutuhan mereka. Dengan demikian perusahaan dapat meningkatkan kepuasan pelanggan.

Kepuasan pelanggan merupakan hal penting karena hasil penjualan perusahaan bersumber dari dua kelompok dasar, yaitu pelanggan baru dan pelanggan yang membeli ulang. Biaya untuk membeli pelanggan baru lebih besar daripada mempertahankan pelanggan yang ada. Oleh karena itu, perusahaan agar dapat mempertahankan pelanggan yang ada dengan jalan membuatnya agar selalu merasa senang. Pelanggan yang puas akan membeli produk kembali kemudian menceritakan produk itu kepada orang lain.

Berdasarkan asumsi diatas mengenai kualitas pelayanan dan kepuasan pelanggan terhadap loyalitas pelanggan, peneliti mencoba mengembangkan penelitian ini, dengan melihat penelitian terdahulu yang sudah banyak dilakukan oleh peneliti, dapat digambarkan sebuah paradigma penelitian sebagai berikut :

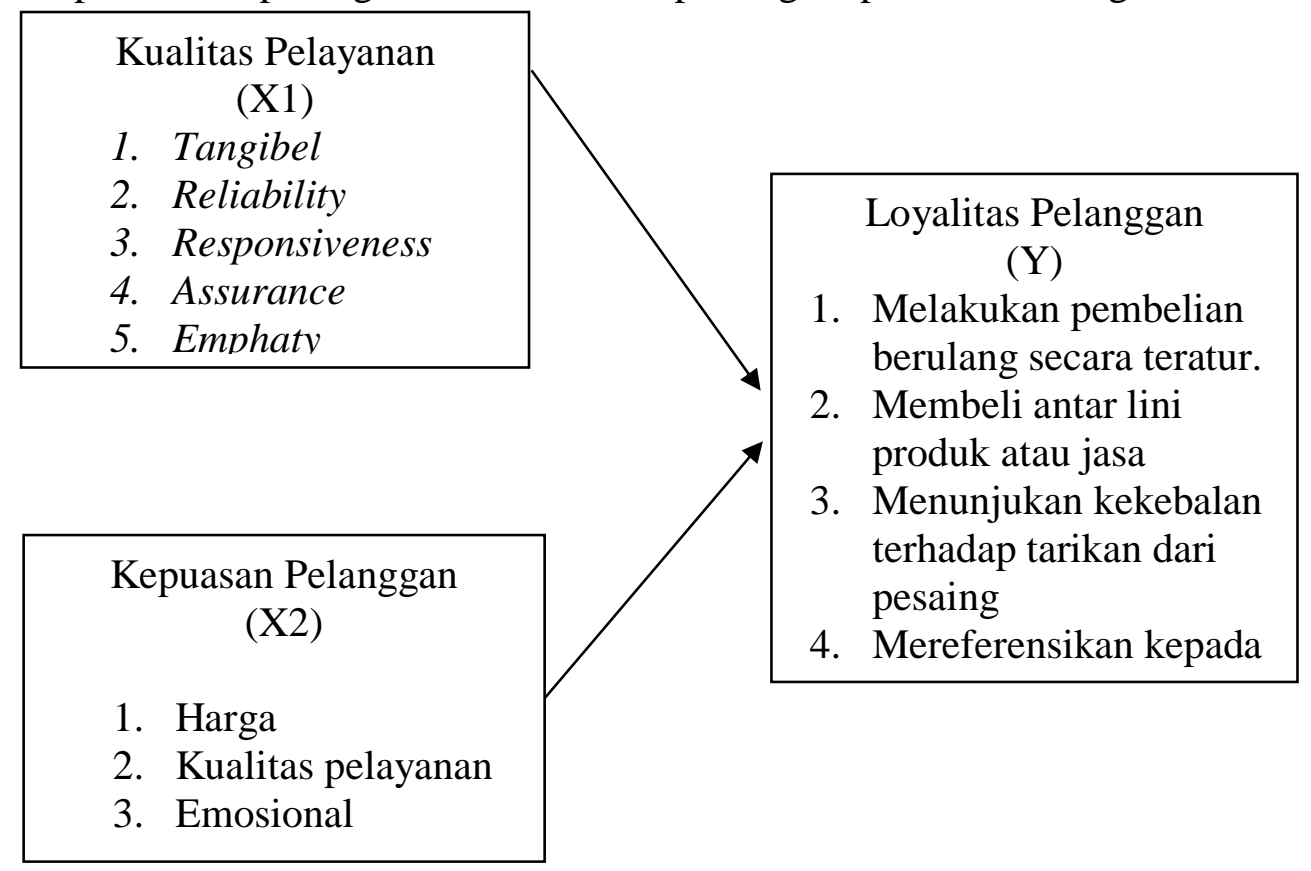

Gambar 1

Paradigma Penelitian Pengaruh kualitas pelayanan dan kepuasan pelanggan terhadap loyalitas pelanggan 


\section{METODE PENELITIAN}

\section{Metode Yang Digunakan}

Dalam penelitian ini metode yang digunakan adalah deskriptif dan pendekatan kuantitatif.

\section{Populasi dan Sampel}

Populasi dalam penelitian ini adalah seluruh pelanggan Hotel Libra Kadipaten Kabuaten Majalengka. Menurut data dari HRD Hotel Libra Kadipaten Kabupaten Majalengka, jumlah pelanggan pada tahun 2018 sebanyak 10690 orang. Sampel dalam penelitian ini adalah 99 responden.

\section{HASIL PENGUJIAN INSTRUMEN PENELITIAN}

\section{Hasil Uji Validitas}

Untuk mencari nilai uji validitas (ketepatan) instrument menggunakan rumus korelasi Product Moment (Sugiyono,2012:183), berikut :

Tabel 1

Hasil Uji Validitas

\begin{tabular}{|c|c|c|c|c|}
\hline \multirow{4}{*}{ variabel } & no item & $\begin{array}{c}\text { Koefisien } \\
\text { Validitas }\end{array}$ & $\mathrm{r}_{\text {kritis }}$ & keterangan \\
\hline \multirow{7}{*}{$\begin{array}{c}\text { Kualitas } \\
\text { Pelayanan }\left(\mathrm{X}_{1}\right)\end{array}$} & 1 & 0,646 & 0.300 & Valid \\
\cline { 2 - 5 } & 2 & 0,585 & 0.300 & Valid \\
\cline { 2 - 5 } & 3 & 0,638 & 0.300 & Valid \\
\cline { 2 - 5 } & 5 & 0,543 & 0.300 & Valid \\
\cline { 2 - 5 } & 7 & 0,500 & 0.300 & Valid \\
\cline { 2 - 5 } & 8 & 0,772 & 0.300 & Valid \\
\cline { 2 - 5 } & 9 & 0,594 & 0.300 & Valid \\
\cline { 2 - 5 } & 10 & 0,298 & 0.300 & Valid \\
\hline \multirow{4}{*}{ Kepuasan $\left(\mathrm{X}_{2}\right)$} & 2 & 0,643 & 0.300 & Valid \\
\cline { 2 - 5 } & 2 & 0,689 & 0.300 & Valid \\
\cline { 2 - 5 } & 4 & 0,692 & 0.300 & Valid \\
\cline { 2 - 5 } & 5 & 0,606 & 0.300 & Valid \\
\cline { 2 - 5 } & 6 & 0,717 & 0.300 & Valid \\
\hline Loyalitas & 1 & 0,629 & 0.300 & Valid \\
\cline { 2 - 5 } Pelanggan $(\mathrm{Y})$ & 2 & 0,553 & 0.300 & Valid \\
\hline
\end{tabular}




\begin{tabular}{|l|l|l|l|l|}
\hline & 3 & 0,694 & 0.300 & Valid \\
\cline { 2 - 5 } & 4 & 0,698 & 0.300 & Valid \\
\hline
\end{tabular}

Berdasarkan table 1 di atas, semua item pertanyaan memiliki koefisien lebih besar dari 0,300 sehingga dapat disimpulkan bahwa item-item pertayaan dapat digunakan untuk mengukur variabel $\mathrm{X} 1, \mathrm{X} 2$ dan $\mathrm{Y}$ dan akan mampu menghasilkan variabel yang akurat sesuai dengan tujuan penelitian.

\section{Uji Reliabilitas}

Metode yang digunakan untuk menguji reliabilitas adalah one shot (pengukuran sekali saja). Pengujian reliabilitas ini akan dibantu dengan program SPSS melalui uji statistik Cronbach Alpha $(\alpha)$. Suatu konstruk dikatakan reliabel jika memberikan nilai $\alpha>0,60$ (Ghozali, 2006).

Tabel 2

Hasil Uji Reliabilitas Instrumen Variabel Penelitian

\begin{tabular}{|c|l|c|c|c|}
\hline No & \multicolumn{1}{|c|}{ Variabel } & $\begin{array}{c}\text { Cronbach's } \\
\text { Alpha }\end{array}$ & $\begin{array}{c}\text { Min } \\
\text { Cronbach's } \\
\text { Alpha yang } \\
\text { disyaratkan }\end{array}$ & Keterangan \\
\hline 1 & Kualitas Pelayanan (X1) & 0.748 & 0,60 & Reliabel \\
\hline 2 & Kepuasan (X2) & 0,725 & 0,60 & Reliabel \\
\hline 3 & Loyalitas Pelanggan (Y) & 0,865 & 0,60 & Reliabel \\
\hline
\end{tabular}

Dari hasil uji coba yang telah dilakukan dapat diketahui bahwa hasil Cronbach's Alpha dari setiap variabel lebih dari standar minimal Cronbach's Alpha yang disyaratkan yaitu 0,60, maka dengan ini variabel kualitas produk, harga dan keputusan pembelian reliabel dan layak di gunakan dalam pengambilan data untuk penelitian ini.

\section{Analisis Verifikatif \\ Uji Normalitas}

Uji normalitas data dalam penelitian ini menggunakan uji KolmogorovSmirnov untuk masing-masing variabel.

Jika data memiliki tingkat signifikansi lebih besar dari 0,05 atau 5\%maka dapat disimpulkan bahwa $\mathrm{HO}$ diterima, sehingga dikatakan data berdistribusi normal (Ghozali, 2006: 163). Ini dapat dilihat pada table dibawah ini :

Tabel.3. Hasil Uji Normalitas Instrumen Variabel Penelitian

\begin{tabular}{|l|l|r|r|r|}
\hline \multicolumn{5}{|c|}{ One-Sample Kolmogorov-Smirnov Test } \\
\hline \multicolumn{2}{|c|}{$\begin{array}{c}\text { Kualitas } \\
\text { pelayanan }\end{array}$} & Kepuasan & \multicolumn{1}{c|}{ Loyalitas } \\
\hline N & 99 & 99 & 99 \\
\hline Normal Parameters & a,b & 38,8384 & 23,0808 & 15,7677 \\
\hline
\end{tabular}




\begin{tabular}{|l|l|r|r|r|}
\hline & Std. Deviation & 4,56407 & 2,92657 & 2,03955 \\
\hline \multirow{3}{*}{ Most Extreme Differences } & Absolute &, 096 &, 206 &, 151 \\
\cline { 2 - 5 } & Positive &, 058 &, 094 &, 074 \\
\cline { 2 - 5 } & Negative &,- 096 &,- 206 &,- 151 \\
\hline Kolmogorov-Smirnov Z &, 958 & 2,051 & 1,506 \\
\hline Asymp. Sig. (2-tailed) &, 318 &, 235 &, 121 \\
\hline \multicolumn{2}{|l|}{ a. Test distribution is Normal. } \\
\hline \multicolumn{4}{|l|}{ b. Calculated from data. } & \multicolumn{4}{|l}{} \\
\hline
\end{tabular}

Berdasarkan hasil pengujian normalitas yang disajikan pada Tabel 3 dapat dilihat bahwa nilai signifikansi variabel penelitian lebih besar dari $\alpha=0,05$ yaitu 0,318 untuk variable kualitas pelayanan, 0,235 untuk variable kepuasan dan 0,121 untuk variable loyalitas pelanggan. Dengan demikian, dapat disimpulkan bahwa ke tiga variabel penelitian ini berdistribusi normal, sehingga dapat dianalisa lebih lanjut.

\section{Analisis Koefisien Korelasi Ganda}

Tabel. 4. Koefisien Korelasi

\begin{tabular}{|c|c|c|c|c|}
\hline \multicolumn{5}{|c|}{ Correlations } \\
\hline & & $\begin{array}{c}\text { Kualitas } \\
\text { pelayanan }\end{array}$ & Kepuasan & Loyalitas \\
\hline \multirow{3}{*}{ Kualitas pelayanan } & Pearson Correlation & 1 &, $922^{* *}$ &, $745^{* *}$ \\
\hline & Sig. (2-tailed) & & ,000 & ,000 \\
\hline & $\mathrm{N}$ & 99 & 99 & 99 \\
\hline \multirow{3}{*}{ Kepuasan } & Pearson Correlation &, $922^{* * *}$ & 1 &, $737^{* *}$ \\
\hline & Sig. (2-tailed) & ,000 & & ,000 \\
\hline & $\mathrm{N}$ & 99 & 99 & 99 \\
\hline \multirow{3}{*}{ Loyalitas } & Pearson Correlation &, $745^{* *}$ &, $737^{* * *}$ & 1 \\
\hline & Sig. (2-tailed) &, 000 &, 000 & \\
\hline & $\mathrm{N}$ & 99 & 99 & 99 \\
\hline
\end{tabular}

\begin{tabular}{|l|c|c|c|c|}
\hline \multicolumn{5}{|c|}{ Model Summary } \\
\hline Model & $\mathrm{R}$ & R Square & $\begin{array}{c}\text { Adjusted R } \\
\text { Square }\end{array}$ & $\begin{array}{c}\text { Std. Error of the } \\
\text { Estimate }\end{array}$ \\
\hline 1 &, $756^{\mathrm{a}}$ &, 571 &, 562 & 1,34925 \\
\hline a. Predictors: (Constant), Kepuasan, Kualitas pelayanan \\
\hline
\end{tabular}
berikut :

Hasil perhitungan korelasi Pearson di atas dapat kita intepretasikan sebagai

1. Hubungan antara kualitas pelayanan dengan loyalitas pelanggan sebesar 0,745 dan masuk dalam kategori kuat. Arah hubungan positif antara kualitas pelayanan dengan loyalitas pelanggan menunjukan bahwa peningkatan kualitas pelayanan cenderung diikuti dengan peningkatan loyalitas pelanggan.

2. Hubungan antara kepuasan dengan loyalitas pelanggan sebesar 0,737 dan masuk dalam kategori kuat. Arah hubungan positif antara kepuasan dengan 
loyalitas pelanggan menunjukan bahwa tingginya kepuasan pada perusahaan cenderung diikuti dengan peningkatan loyalitas pelanggan.

3. Hubungan antara kualitas pelayanan dengan kepuasan sebesar 0,922 dan masuk dalam kategori sangat kuat. Arah hubungan positif antara kualittas pelayanan dengan kepercayaan menunjukan bahwa kualitas pelayanan pada perusahaan cenderung diikuti dengan peningkatan kepuasan.

4. Keeratan hubungan antara variabel independen dengan variabel dependen secara simultan ditunjukkan dengan nilai $\mathrm{R}=0.571$ Angka ini menunjukkan keeratan hubungan yang cukup kuat seluruh variabel independen $\mathrm{X}$ terhadap variabel dependen $\mathrm{Y}$.

Analisis Koefisien Regresi Ganda

Tabel.5. Koefisien Regresi

\begin{tabular}{|c|c|c|c|c|c|c|}
\hline \multicolumn{7}{|c|}{ Coefficients $^{\mathrm{a}}$} \\
\hline \multirow{2}{*}{\multicolumn{2}{|c|}{ Model }} & \multicolumn{2}{|c|}{ Unstandardized Coefficients } & \multirow{2}{*}{$\begin{array}{c}\begin{array}{c}\text { Standardized } \\
\text { Coefficients }\end{array} \\
\text { Beta } \\
\end{array}$} & \multirow[t]{2}{*}{$\mathrm{t}$} & \multirow[t]{2}{*}{ Sig. } \\
\hline & & $\mathrm{B}$ & Std. Error & & & \\
\hline \multirow{3}{*}{1} & (Constant) & 2,814 & 1,168 & & 2,409 &, 018 \\
\hline & Kualitas pelayanan & 195 & ,077 & ,437 & 2,538 & ,013 \\
\hline & Kepuasan & 233 & 120 & ,334 & 1,941 & 015 \\
\hline
\end{tabular}

Melalui hasil pengolahan data seperti diuraikan diatas maka dapat dibentuk model prediksi variabel kualitas pelayanan dan kepercayaan terhadap loyalitas pelanggan sebagai berikut :

$$
\mathrm{Y}=2,814+0,195 \mathrm{X}_{1}+0,233 \mathrm{X}_{2}
$$

Berdasarkan persamaan prediksi di atas, maka dapat diinterpretasikan koefisien regresi dari masing-masing variabel independen sebagai berikut:

1. Konstanta sebesar 2,814 mengandung arti jika kualitas pelayanan dan kepuasan nilainya adalah nol maka loyalitas pelanggan adalah sebesar 2,814.

2. Koefisien regresi kualitas pelayanan sebesar 0,195 , menyatakan bahwa setiap penambahan satu satuan skor kualitas pelayanan akan meningkatkan loyalitas pelanggan sebesar 0,195, dengan asumsi variabel bebas kepuasan konstan.

3. Koefisien regresi kepuasan sebesar 0,233, menyatakan bahwa setiap penambahan satu satuan skor kepuasan akan meningkatkan loyalitas pelanggan sebesar 0,233, dengan asumsi variabel bebas kualitas pelayanan konstan.

\section{Koefisien Determinasi}

Tabel.6. Koefisien Determinasi

\begin{tabular}{|l|c|c|c|c|}
\hline \multicolumn{5}{|c|}{ Model Summary } \\
\hline Model & $\mathrm{R}$ & R Square & $\begin{array}{c}\text { Adjusted R } \\
\text { Square }\end{array}$ & $\begin{array}{c}\text { Std. Error of the } \\
\text { Estimate }\end{array}$ \\
\hline 1 &, $756^{\mathrm{a}}$ &, 571 &, 562 & 1,34925 \\
\hline a. Predictors: (Constant), Kepuasan, Kualitas pelayanan \\
\hline
\end{tabular}

Berdasarkan perhitungan dan tabel output di atas, diketahui bahwa pengaruh secara bersama yang diberikan kualitas pelayanan dan kepuasan secara simultan 
terhadap loyalitas pelanggan adalah sebesar 0,571 atau $57,1 \%$, sedangkan sebanyak 0,429 $\left(1-\mathrm{R}^{2}\right)$ atau $42,9 \%$ sisanya merupakan besar kontribusi pengaruh dari faktor lain yang tidak diteliti (epsilon).

\section{Pengujian Hipotesis}

\section{Pengujian Hipotesis Secara Simultan}

Nilai statistik uji F dapat diketahui dari tabel output berikut:

Tabel . 7. Uji Hipotesis Simultan

\begin{tabular}{|l|l|r|r|r|r|r|}
\hline \multicolumn{7}{|c|}{ ANOVA $^{\text {a }}$} \\
\hline Model & Sum of Squares & df & Mean Square & F & Sig. \\
\hline \multirow{4}{*}{1} & Regression & 232,892 & 2 & 116,446 & 63,965 &, $000^{\mathrm{b}}$ \\
\cline { 2 - 7 } & Residual & 174,764 & 96 & 1,820 & & \\
\cline { 2 - 7 } & Total & 407,657 & 98 & & & \\
\hline \multicolumn{7}{|l}{ a. Dependent Variable: Loyalitas } \\
\hline
\end{tabular}

Berdasarkan tabel output di atas, dapat diketahui nilai $F_{\text {hitung }}$ sebesar 63,965. Nilai ini akan dibandingkan dengan nilai F-tabel. Dengan $\alpha=0,05, \mathrm{db} 1=2 \mathrm{dan} \mathrm{db}$ $2=96$, diketahui nilai F-tabel sebesar 3,09. Dari nilai-nilai di atas, diketahui nilai $F_{\text {hitung }}(63,965)>F_{\text {tabel }}(3,09)$, sehingga $\mathrm{H} 0$ ditolak dan Ha diterima, artinya kualitas pelayanan dan kepuasan secara bersama-sama berpengaruh positif dan signifikan terhadap loyalitas pelanggan pada Hotel Libra Kabupaten Majalengka.

\section{Pengujian Hipotesis Parsial}

Tabel.8. Hasil Uji Hipotesis Parsial (Uji t) X1

\begin{tabular}{|c|c|c|c|c|c|c|}
\hline \multicolumn{7}{|c|}{ Coefficients $^{\mathrm{a}}$} \\
\hline \multirow{2}{*}{\multicolumn{2}{|c|}{ Model }} & \multicolumn{2}{|c|}{ Unstandardized Coefficients } & \multirow{2}{*}{$\begin{array}{c}\begin{array}{c}\text { Standardized } \\
\text { Coefficients }\end{array} \\
\text { Beta } \\
\end{array}$} & \multirow[t]{2}{*}{$\mathrm{t}$} & \multirow[t]{2}{*}{ Sig. } \\
\hline & & $\mathrm{B}$ & Std. Error & & & \\
\hline \multirow{3}{*}{1} & (Constant) & 2,814 & 1,168 & & 2,409 &, 018 \\
\hline & Kualitas pelayanan & , 195 & ,077 & 437 & 2,538 & 013 \\
\hline & Kepuasan & 233 & 120 &, 334 & 1,941 &, 015 \\
\hline
\end{tabular}

Berdasarkan tabel di atas, diketahui nilai thitung untuk kualitas pelayanan adalah sebesar 2,538. Nilai thitung ini akan dibandingkan dengan nilai tabel pada tabel distribusi t, dengan $\alpha$ 0,05 dan df (n-k-1) 96 untuk pengujian 2 pihak diperoleh nilai $t_{\text {tabel }}$ sebesar 1.66088. Karena nilai $t_{\text {hitung }}(2,538)$ lebih besar dari nilai $t_{\text {tabel }}(1.66088)$ dan berada didaerah penolakan Ho sehingga sesuai dengan kriteria pengujian hipotesis adalah menolak Ho dan menerima Ha yang berarti terdapat pengaruh positif dan signifikan kualitas pelayanan terhadap loyalitas pelanggan pada Hotel Libra Kabupaten Majalengka.

a. Uji Hipotesis Parsial $\mathrm{X}_{2}$ Terhadap $\mathrm{Y}$

Tingkat signifikansi $(\alpha)$ yang digunakan dalam pengujian ini sebesar 0,05 dengan kriteria pengujiannya adalah tolak Ho dan terima Ha jika nilai $t_{\text {hitung }}$ lebih besar dari nilai $t_{\text {tabel. }}$. Berdasarkan pada tabel 4.34 di atas, diketahui nilai 
$t_{\text {hitung }}$ untuk kepuasan adalah sebesar 1,941. Nilai thitung ini akan dibandingkan dengan nilai $t_{\text {tabel }}$ pada tabel distribusi t, dengan $\alpha 0,05$ dan df (n-k-1) 96 untuk pengujian 2 pihak diperoleh nilai $t_{\text {tabel }}$ sebesar 1.66088. Karena nilai $t_{\text {hitung }}$ $(1,941)$ lebih besar dari nilai $t_{\text {tabel }}(1.66088)$ dan berada didaerah penolakan Ho sehingga sesuai dengan kriteria pengujian hipotesis adalah menolak Ho dan menerima Ha yang berarti Terdapat pengaruh positif dan signifikan kepuasan terhadap loyalitas pelanggan pada Hotel Libra Kabupaten Majalengka.

b. Uji Hipotesis Parsial $\mathrm{X}_{2}$ Terhadap $\mathrm{Y}$

Tingkat signifikansi $(\alpha)$ yang digunakan dalam pengujian ini sebesar 0,05 dengan kriteria pengujiannya adalah tolak Ho dan terima Ha jika nilai thitung lebih besar dari nilai tabel. Berdasarkan pada tabel 8 di atas, diketahui nilai thitung untuk kepuasan adalah sebesar 1,941. Nilai thitung ini akan dibandingkan dengan nilai $t_{\text {tabel }}$ pada tabel distribusi $t$, dengan $\alpha 0,05$ dan df (n-k-1) 96 untuk pengujian 2 pihak diperoleh nilai $t_{\text {tabel }}$ sebesar 1.66088. Karena nilai $t_{\text {hitung }}$ $(1,941)$ lebih besar dari nilai $t_{\text {tabel }}(1.66088)$ dan berada didaerah penolakan Ho sehingga sesuai dengan kriteria pengujian hipotesis adalah menolak Ho dan menerima Ha yang berarti Terdapat pengaruh positif dan signifikan kepuasan terhadap loyalitas pelanggan pada Hotel Libra Kabupaten Majalengka.

\section{KESIMPULAN}

Berdasarkan hasil penelitian dan pembahasan yang berkaitan dengan pengaruh kualitas pelayanan dan kepuasan terhadap loyalitas pelanggan pada Hotel Libra Kabupaten Majalengka, maka dapat ditarik kesimpulan :

1. Hasil perhitungan variabel kualitas pelayanan didapat nilai sebesar $77,68 \%$, sehingga jika dibandingkan dengan kriteria untuk pengambilan keputusan yang dikemukakan oleh Narimawati (2008:83) berada di antara 68\% -84\% atau masuk dalam kategori tinggi/baik.

2. Hasil perhitungan variabel kepuasan didapat nilai sebesar $75,53 \%$, sehingga jika dibandingkan dengan kriteria untuk pengambilan keputusan yang dikemukakan oleh Narimawati (2008:83) berada di antara $68 \%-84 \%$ atau masuk dalam kategori tinggi/baik.

3. Hasil perhitungan variabel loyalitas pelanggan didapat nilai sebesar $78,84 \%$, sehingga jika dibandingkan dengan kriteria untuk pengambilan keputusan yang dikemukakan oleh Narimawati (2008:83) berada di antara 68\% $-84 \%$ atau masuk dalam kategori tinggi/baik.

4. Terdapat pengaruh positif dan signifikan kualitas pelayanan terhadap loyalitas pelanggan. Karena nilai $t_{\text {hitung }}(2,538)$ lebih besar dari nilai $t_{\text {tabel }}(1.66088)$ dan berada didaerah penolakan Ho sehingga sesuai dengan kriteria pengujian hipotesis adalah menolak Ho dan menerima $\mathrm{Ha}$

5. Terdapat pengaruh positif dan signifikan kepuasan terhadap loyalitas pelanggan. Karena nilai thitung $(1,941)$ lebih besar dari nilai tabel $(1.66088)$ dan berada didaerah penolakan Ho sehingga sesuai dengan kriteria pengujian hipotesis adalah menolak Ho dan menerima $\mathrm{Ha}$ 
6. Kualitas pelayanan dan kepuasan secara bersama-sama berpengaruh positif dan signifikan terhadap loyalitas pelanggan. Karena nilai $F_{\text {hitung }}(63,965)>F_{\text {tabel }}$ (3,09), sehingga H0 ditolak dan Ha diterima, artinya kualitas pelayanan dan kepuasan secara bersama-sama berpengaruh positif dan signifikan terhadap Saran loyalitas pelanggan pada Hotel Libra Kabupaten Majalengka.

Saran yang bisa disampaikan dari hasil penelitian yang didapat adalah sebagai berikut :

1 Kualitas Pelayanan Hotel Libra Kabupaten Majalengka sebaiknya harus di tingkatkan kembali terhadap pelanggan yang datang terhadap Hotel Libra Kabupaten Majalengka dan meningkatkan pelayanan proses serta meningkatkan kebersihan ruangan.

2 Kepuasan Hotel Libra Kabupaten Majalengka sudah berjalan dengan baik tapi perlu ditingkatkan lagi terutama kepuasan terhadap harga.

3 Loyalitas terhadap Hotel Libra Kabupaten Majalengka sudah sangat baik sehingga pelanggan yang datang untuk menginap sudah berjalan dengan baik Cuma perlu ditingkatkan lagi.

\section{DAFTAR PUSTAKA}

Ghozali, I. (2006). Aplikai Analisis Multivarite dengan SPSS, Cetakan Keempat,. Semarang: Badan Penerbit Universitas Diponegoro, .

Griffin, J. (2005). Customer Loyalty : Menumbuhkan dan Mempertahankan Kesetiaan Pelanggan. Alih Bahasa : Dwi Kartini Yahya dan kawan-kawan. . Jakarta: Erlangga

Kotler, P. (2013). Manajemen Pemasaran, Edisi 13. Jakarta : Erlangga.

Kotler, P., \& Armstrong, G. (2014). Principle Of Marketing, 15th edition. New Jersey: Pearson Prentice Hall.

Nasution, N. (2015). Manajemen Mutu Terpadu. Bogor: Ghalia Indonesia

Riduwan. (2013). Skala Pengukuran Vaiabel-variabel Penelitian. Bandung: Alfabeta.

Sugiyono. (2011). Metode Penelitian Kuantitatif dan Kualitatif . Bandung: CV.Alfabeta.

Tjiptono, F. (2014). Pemasaran Jasa: Prinsip, Penerapan dan Penelitian. Yogyakarta: Andi Offset.

Tjiptono, F., \& Chandra, G. (2011). Service, Quality and Satisfaction. Yogyakarta: Andi.

Zeithaml, Parasuraman, \& Malhotra. (2002). E-S-QUAL A Multiple-Item Scale for Assessing Electronic Service Quality. New York: Free Press .. 
